\title{
Evaluation of Academic Self - Efficacy Perceptions and Instructional Dissent Attitudes of Teacher Candidates in Terms of Classroom Management
}

\section{Remzi Yıldırım ${ }^{2}$ Hamit Özen²}

'Faculty of Education, Manisa Celal Bayar University, Demirci, Turkey Email:yildirimremzi@hotmail.com Tel: +905056184269

'Faculty of Education, Eskisehir Osman Gazi University, Eskisehir, Turkey

Email:hamitozen@hotmail.com Tel:+905302520724

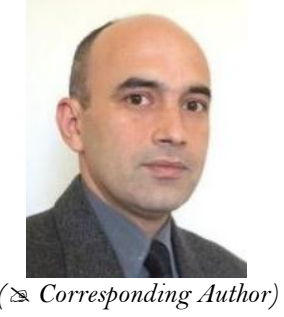

Abstract

In this study, academic self-efficacy perceptions and instructional dissent attitudes of teacher candidates have been examined and the findings have been evaluated in terms of classroom management. The population consists 2409 teacher candidates from the Faculty of Education in Eskisehir Osman Gazi University in the fall semester of 2018. Descriptive statistics were used while evaluating their perceptions and attitudes. Non-parametric tests were applied in the analysis since the data distribution was not normal. Mann Whitney U Analysis was used to determine whether there was a significant difference in their academic self-efficacy perceptions and instructional dissent attitudes by gender, while Kruskal Wallis Analysis was used to determine whether there was a significant difference by departments. Spearman's Rank Correlation Analysis was used to determine whether there is a relationship between their academic self-efficacy perceptions and instructional dissent attitudes. According to the findings, it has been seen that the academic self-efficacy perceptions of teacher candidates are at a normal level and instructional dissent attitudes are at a low level. The total scores of teacher candidates calculated for the whole academic self-efficacy perceptions and coping subdimension were significantly different in favor of female candidates. There was no significant difference by departments. There was no significant difference in instructional dissent by gender and departments. It has been found out that there is a low-level relationship between the total scores of academic self-efficacy perception levels and instructional dissent attitudes of teacher candidates.

Keywords: Academic self - efficacy, Instructional dissent, Classroom management, Classroom environment, Teacher candidates, Teacher training.

Citation | Remzi Yıldırım; Hamit Özen (2019). Evaluation of Academic Self - Efficacy Perceptions and Instructional Dissent Attitudes of Teacher Candidates in Terms of Classroom Management. Asian Journal of Education and Training, 5(2): 299308.

History:

Received: 21 January 2019

Revised: 25 February 2019

Accepted: 27 March 2019

Published: 12 April 2019

Licensed: This work is licensed under a Creative Commons Attribution 3.0 License (c)

Publisher: Asian Online Journal Publishing Group
Contribution/Acknowledgement: Both authors contributed to the conception and design of the study.

Funding: This study received no specific financial support.

Competing Interests: The authors declare that they have no conflict of interests.

Transparency: The authors confirm that the manuscript is an honest, accurate, and transparent account of the study was reported; that no vital features of the study have been omitted; and that any discrepancies from the study as planned have been explained.

Ethical: This study follows all ethical practices during writing.

\section{Contents}

1. Introduction

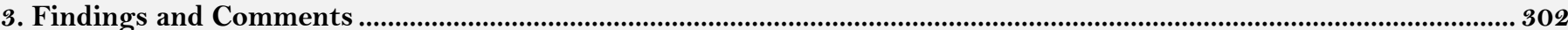

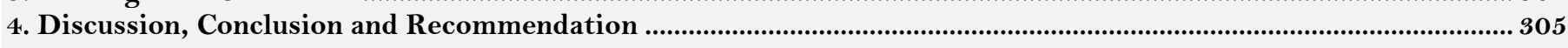

References. 


\section{Introduction}

It can be said that the knowledge has become one of the most important power sources in the present day, considering the knowledge level of humanity that increases continually and the advantages provided to individuals and societies with increasing knowledge level. Today's societies have been trying to build education systems in the most correct way to develop and convey the information they have, in order to survive and continue their development. Education systems should be within the required structure in terms of both quantity and quality, and this situation should be reflected in the classroom environment. The effect of classroom management is inevitable for achieving the target success in classroom environments. Raising independent, critical thinker, responsible individuals with democratic values (Sişman et al., 2010) will affect this situation positively and contribute to the development of learning environment with the classroom management strategies followed. The studies conducted show that learning environments are affected by social and cultural factors (Aldridge and Fraser, 2000). In this sense, it can be said that one of the important expectations from educational environments is to encourage academic study in a way that will contribute to students' development and to support critical thinking in a democratic structure.

Just like in almost every field, in academic studies as well it can be a determining factor in achieving goals that the individuals find themselves sufficient in that field. This situation, which is referred to as academic self - efficacy in literature, as Terzi and Celik (2018) stated, is an individual's perception of being able to perform an academic task at the target success level and it has a positive relationship with academic motivation. As Bandura (1997) puts forth, self - efficacy, which is the belief of the individual in organizing and performing an action, can be said to make an important contribution to the student motivation and success within the educational process. The self efficacy theory developed by Bandura has an important role on individual behaviors and it increases the academic performance of students (Aktaş, 2017). Self - efficacy perception has some effects on four major psychological processes which are cognitive, motivational, affective and selection processes (Bandura, 1994) and it is the belief or confidence in the competences of achieving academic goals (Drago et al., 2016). In this sense, it can be said that the self - efficacy belief that the individual perceives makes him / her feel confident in achieving his / her goals.

In order for systems of education to make both individuals and societies achieve their goals, educational process should be quality. According to Akpinar et al. (2006) there should be a harmony between students, teachers and the program for a qualified education system. The attitudes and behaviors of the teachers in the classroom management process will facilitate the harmony between students and the program and affect the success of students. In the classroom management process, it is important for the teacher to give students the sense of confidence and for students to be confident in achievement of the program. One of the factors to reinforce this trust is students' self - efficacy belief and teachers should lead this situation through practices. Kandemir (2010) revealed the dimensions of coping with academic problems, academic effort and academic planning about academic self efficacy. It can be said that the teacher has a positive effect on the dimensions related to the classroom management processes.

In today's world, the ability of individuals and societies to maintain their lives at the desired point is closely related to their competitive power. Free and critical thinking needs to be supported considering the importance of the ability to make an innovation in providing competition. It is possible to develop free and critical thinking by assimilating democracy within the educational processes that prepare individuals and societies for life. However, it can be said that the negative attitudes of the teachers will negatively affect the democracy in the classroom and provide a basis for students' attitudes called instructional dissent. Martin et al. (2015) stated that negative teacher behaviors play a role in the emergence of instructional dissent. Instructional dissent can be regarded as expressive dissent, rhetorical dissent and vengeful dissent (Goodboy, 2011). While negative teacher behaviors are determinant in the emergence of expressive and vengeful dissent, it can be said that the low self - efficacy belief is determinant when the rhetorical dissent remains lower than others (Martin et al., 2015). Dağl et al. (2017) stated that students express their feelings clearly by expressive dissent, they try to persuade the teacher to correct an existing mistake by rhetorical dissent, and they try to harm teacher's reputation by vengeful dissent. In this sense, it can be said that negative teacher behaviors and low self - efficacy beliefs play a role in leading students to exhibit instructional dissent attitudes. In addition, it is possible to make positive contributions to the classroom management processes with the teachers getting closer with their students within certain limits, opening themselves to the students as a source of inspiration and avoiding negative behaviors (Goodboy et al., 2014).

In this context, the purpose of this study is to determine the academic self - efficacy and instructional dissent levels of teacher candidates, to examine the relationship between their academic self - efficacy and instructional dissent levels and to evaluate the findings obtained in terms of the classroom management. For this purpose, the problem status created as "What is the level of teacher candidates' academic self - efficacy perceptions and instructional dissent attitudes?" has been handled within the scope of below sub - problems:

1. What are the descriptive statistics on the academic self - efficacy perceptions and instructional dissent attitudes of teacher candidates?

2. Do teacher candidates' academic self - efficacy perceptions differ significantly by their gender and department?

3. Do teacher candidates' instructional dissent attitudes differ significantly by their gender and departments?

4. Is there a relationship between academic self - efficacy perceptions and instructional dissent attitudes of teacher candidates?

It is expected to contribute to the field of classroom management and consequently to the operation of the educational process through the results obtained as a result of the findings obtained within the framework of the problem indicated in the study. The results of the study are limited to the population of the study and to the data collected from the population of the study. Moreover, self - efficacy and instructional dissent levels of the teacher candidates investigated in the study are limited to the measurement tools used in the study and to sub - dimensions of the related measurement tools. 


\section{Methodology}

In this study, which was carried out according to quantitative research methods known as a positive opinion, the investigated subject was observed independently and objectively, measured and analyzed as indicated by Büyüköztürk et al. (2013) According to Simsek (2012) the subject of the study can be conducted over the whole population or the sample representing the population (Karasar, 2012) within the general survey models that reveal the reality as is. The general survey model was used in this study.

\subsection{Population and Sampling}

In the study, Eskisehir Osman Gazi University, Faculty of Education was determined as the population of the study. It was determined that 2409 teacher candidates received education in the related faculty in the fall semester of 2018 and it was aimed to reach 332 teacher candidates for sampling by taking into consideration the $95 \%$ confidence level and 5\% error margin calculation of Sahin (2012). In this meaning the data was collected from 336 teacher candidates. When selecting samples, the number of stratified samples was determined by taking the gender of the teacher candidates and the departments they studied into consideration and then the participants were included in the sample by simple random sampling method. The population and sampling status as gender and department are given in Table 1.

Table-1. Population and sampling status of the study.

\begin{tabular}{|c|c|c|c|c|c|c|}
\hline Department & Female(N) & Female(n) & Male(N) & Male(n) & $\mathbf{N}$ & $\mathbf{n}$ \\
\hline Comp. and Instr. Tech. Teaching & 79 & 11 & 137 & 19 & 216 & 30 \\
\hline Science Teaching & 226 & 31 & 57 & 9 & 283 & 40 \\
\hline English Teaching & 165 & 23 & 78 & 10 & 243 & 33 \\
\hline Primary Mathematics Teaching & 231 & 32 & 64 & 10 & 295 & 42 \\
\hline Preschool Teaching & 210 & 29 & 31 & 4 & 241 & 33 \\
\hline Special Education Teaching & 106 & 15 & 101 & 13 & 207 & 28 \\
\hline Psychological Counseling and Guidance & 433 & 61 & 187 & 27 & 620 & 88 \\
\hline Primary School Teaching & 236 & 33 & 68 & 9 & 304 & 42 \\
\hline Total & 1686 & 235 & 723 & 101 & 2409 & 336 \\
\hline
\end{tabular}

Source: Sampling of the study according to $95 \%$ confidence level and $5 \%$ error margin.

\subsection{Data Collection Tools}

In the study, "Academic Self - Efficacy scale "developed by Kandemir (2010) and "Instructional Dissent Scale" developed by Goodboy (2011) and adapted to Turkish by Dağlı et al. (2017) were used. The first scale belongs to Kandemir (2010) and the second one belongs to Dağlı et al. (2017).

While "Academic Self - Efficacy Scale" developed to determine academic self - efficacy perceptions of students were prepared by Kandemir (2010) firstly the relevant literature was reviewed and an item pool of 29 items was created. Subsequently, the items indicated were sent out to 6 experts in order to get their opinion within the scope of the validity of the scale and 2 items were eliminated and the number of items was decreased to 27 . Then, the pre - application was carried out with 468 university students. The data showed that the Kaiser Mayer Olkin (KMO) coefficient (.93) and Bartlett test result $\left(\chi^{2}=3810.52, \mathrm{p}<0.001\right)$ were significant. In order to determine the factor structure of the scale, Principle Components Analysis (PCA) and Varimax rotation were performed. With this analysis, it has been determined that the scale has a 3 - factor structure. The variance explained by the first factor is 27.739; the second factor's variance is 14.529 and the third factor's variance is 13.622. The total variance explained by the three - factor structure has been found to be 55.891. Factors were named as coping with academic problems, academic effort and academic planning, respectively. Then, confirmatory factor analysis was performed. The chi - square value $\left(\chi^{2}\right)$ was found to be 557.76 and the degree of freedom was 149 . It was decided that the $3-$ factor structure had good fit values as a result of the fact that the division of chi square by its degree of freedom $\left(\chi^{2} / \mathrm{sd}\right.$.) was found to less than 5 in the 3.74 format. In addition to the confirmatory factor analysis, Cronbach alpha internal consistency coefficients which is calculated based on item analysis was checked to evaluate the reliability of the scores obtained. These coefficients were found to be .90 for the first factor, .78 for the second factor, .77 for the third factor, and .92 for the whole scale. The total item correlations for each dimension ranged from .36 to .67 and then the scale was finalized.

The instructional dissent scale is a measuring tool developed by Goodboy (2011) in order to determine student attitudes towards teacher - driven negative behaviors and unfair decisions within the classroom. Some teacher driven negative behaviors triggering instructional dissent have been determined as; unfair exams, unjustified scoring, inefficient teaching style, violation of classroom principles and curricula, improper behaviors and non feedback. The instructional dissent attitudes that arise against these problems have been determined as 3 dimensions which are expressive, rhetorical and vengeful dissent. The instructional dissent scale was adapted to Turkish by Dağlı et al. (2017). The scale was first translated from English to Turkish by 6 experts. Then, it was checked by 4 experts who are competent in the fields of content, measurement and evaluation and some changes were made upon the received suggestions. Then this version of the scale was again translated into English by the back - translation method by 2 independent experts working in the field of education management and who have a good command of English and some semantic shifts were corrected. Thus, consistency has been provided in terms of language between the original scale and its Turkish translation. In addition, 30 university students studying in English Department were firstly applied the English version of the scale, after one week they were applied the Turkish version of the scale within the scope of language equivalence. The correlation between two practices' scores was checked by Pearson moments correlation coefficient and a high - level relationship was found as $\mathrm{r}=.70$ ( $\mathrm{p}=.01$ ). Then 424 high school students were applied the scale and exploratory factor analysis and confirmatory factor analysis were applied within the scope of structure validity. As a result of exploratory factor analysis, Kaiser Meyer Olkin (KMO) coefficient (.85) and Bartlett Sphericity test result $\left(\chi^{2}=2898.38, \mathrm{p}<0.001\right)$ were found to be significant. As a result of the exploratory factor analysis conducted through principal components and direct 
rotation, it was determined that there were 3 factors overlapping with the items of the original scale. The exploratory scores of the factors were found to be 12.80 for expressive dissent, 14.46 for rhetorical dissent, 18.85 for vengeful dissent, and 46.10 for the whole scale. It was seen that item factor loads ranged between .63 and .83 within a 22 item - scale. Then, confirmatory factor analysis was performed, and structure validity was ensured with the fit indices obtained. In order to test the reliability of the scale, the internal consistency (Cronbach Alpha) coefficient (.80) and Spearman - Brown coefficients (between 0.71 and 0,85 ) were reached through the split - half method, and the scale was decided to be reliable.

\subsection{Analysis of Data}

The data obtained within the scope of the study was analyzed by SPSS 23 program and significance level was taken as .05.

When evaluating the descriptive statistics on the first sub - problem of the study which is academic self efficacy perceptions and instructional dissent attitudes, minimum, maximum, arithmetic mean and standard deviation values were used.

Before analyzing other sub - problems, it was checked by Kolmogorov Smirnov Test whether the data set is distributed normally. It has been found out that the significance level results for subdimensions of each scale and the whole of the scale does not show a normal distribution $(\mathrm{p}=.00)$ According to the results obtained, it was decided to use the test groups known as nonparametric tests in the analysis of the data.

For the second sub - problem of the study; Mann Whitney U Analysis was used when checking whether there exists any significant difference in academic self - efficacy perceptions by gender, Kruskal Wallis Analysis was used when checking whether there exists any significant difference by departments.

For the third sub - problem of the study; Mann Whitney U Analysis was used when checking if there exists any significant difference in instructional dissent attitudes by gender, Kruskal Wallis Analysis was used when checking is there exists any significant difference by departments.

For the fourth sub - problem of the study; Spearman's Rank Correlation Coefficient Analysis was used to determine whether there exists any relationship between academic self - efficacy perceptions and instructional dissent attitudes.

\section{Findings and Comments}

In this chapter, the findings and comments obtained within the framework of the sub problems related to the evaluation of academic self - efficacy perceptions and instructional dissent attitudes of teacher candidates are indicated.

\subsection{Findings and Comments on the First Sub-Problem}

The findings and comments obtained related to the first sub - problem "What are the descriptive statistics on the academic self - efficacy perceptions and instructional dissent attitudes of teacher candidates?" are given in Table 2 and Table 3.

Table-2. Descriptive statistics on academic self - efficacy perception levels of teacher candidates.

\begin{tabular}{l|c|c|c|c|c}
\hline Dimensions & $\mathbf{n}$ & Minimum & Maximum & $\mathbf{x}$ & $\boldsymbol{s d}$ \\
\hline Self-Efficacy / Coping & 336 & 13,00 & 55,00 & 37,6310 & 7,31105 \\
\hline Self-Efficacy / Effort & 336 & 4,00 & 20,00 & 14,9167 & 2,90428 \\
\hline Self-Efficacy / Planning & 336 & 5,00 & 20,00 & 13,3899 & 2,91979 \\
\hline Self-Efficacy / Whole & 336 & 27,00 & 95,00 & 65,9375 & 11,89753 \\
\hline
\end{tabular}

The arithmetic means of teacher candidates' total academic self - efficacy perception score has been found 65,93 (frequently). The averages for the sub - dimensions are; 37.63 (frequently) for coping, 14.91 (frequently) for effort, 13.38 (frequently) for planning, respectively. The lowest total academic self - efficacy perception scores have been found 27 (rarely) and highest score is 95 (always). Considering minimum values, it has been determined that the effort sub - dimension has the lowest level with 4 points (never).

In the light of the findings, it has been observed that teacher candidates' academic self - efficacy perceptions and sub - dimensions have been at a moderate level as a whole. Similar findings have also been found in the study where Saracaloğlu et al. (2017) measure academic self - efficacy perceptions of classroom teacher candidates. This can be interpreted as the fact that teacher candidates consider themselves to be at a low level in terms of academic self - efficacy and they get weak in terms of making effort.

In the dimension of coping, the item of "My academic skills have been remarkable for other students" received the lowest score with an arithmetic mean of 2,17 (rarely). In the coping dimension, the item of "If I have a problem with my courses, I can usually think about ways to overcome the problem" received the highest score with an arithmetic mean of 3,83 (frequently). The item with the lowest score in the dimension of effort is "I believe that I have different skills than others in preparation or presentation of homework or projects" with an arithmetic mean of 3.22 (sometimes). The item with the highest score in the dimension of effort is "I can overcome the problems related to my lessons with my personal effort" with and arithmetic mean of 4.01 (frequently). Within the dimension of planning, the item called "I think I am planned while studying my lessons" received the lowest score with an arithmetic mean of 3.12 (sometimes). In the dimension of planning, the item of "I can use many methods to solve the problems I encounter in my studies (preparing homework / projects, getting prepared for exams, etc.)" received the highest score with an arithmetic mean of 3,57 (frequently).

Coban and Sanalan (2002) has pointed out that science teacher candidates' self - efficacy perceptions increase when they design an original experiment. In this study, considering the items with the lowest score average from the dimensions of coping and effort, it can be said that teacher candidates cannot place themselves in a different 
point than their other friends within the scope of academic self - efficacy or they cannot qualify themselves as original. This situation can be considered as one of the reasons that decrease the academic self - efficacy perception. On the other hand, considering the items with the highest score average from each dimension, it can be said that teacher candidates feel themselves perseverance to overcome the difficulties they encounter. In their study conducted with teacher candidates, Celik et al. (2018) found a positive relationship between self - efficacy and perseverance. In this sense, it can be said that individuals without self - efficacy in works that require perseverance, have difficulty in performing their duties (Bandura, 1989, cited from Kotaman (2008)).

Table-3. Descriptive statistics on instructional dissent attitude levels of teacher candidates.

\begin{tabular}{l|c|c|c|c|c}
\hline Dimensions & $\mathbf{n}$ & Minimum & Maximum & $\mathbf{x}$ & sd \\
\hline Instructional Dissent / Expressive & 336 & 10,00 & 50,00 & 24,8185 & 7,49964 \\
\hline Instructional Dissent / Rhetorical & 336 & 6,00 & 30,00 & 17,3363 & 5,52849 \\
\hline Instructional Dissent / Vengeful & 336 & 6,00 & 30,00 & 7,3036 & 2,96700 \\
\hline Instructional Dissent / Whole & 336 & 22,00 & 110,00 & 49,4583 & 11,85175 \\
\hline
\end{tabular}

Source: Descriptive statistics obtained from primary data.

The arithmetic mean of the total score of teacher candidates' instructional dissent attitudes is 49.45 (sometimes). The averages for the sub - dimensions are; 24,81 (sometimes) for the expressive dissent, 17.33 (sometimes) for the rhetorical dissent, and 7.30 (rarely) for the vengeful dissent, respectively. It was observed that the lowest total instructional dissent attitude score is 22 (never) and highest score is 110 (always). When the minimum values are considered, it has been determined that the subdimensions of rhetorical dissent and vengeful dissent remained at the lowest level with an average score of 6 (never).

According to the findings obtained, it can be said that teacher candidates do not exhibit instructional dissent attitudes much. Considering that Goodboy (2011) pointed out negative teacher behaviors predominantly affect the emergence of instructional dissent, and that Johnson and LaBelle (2014) suggest a positive learning environment is created when teachers approach to their students temperately, it can be commented that obtaining these findings is an expected situation. It can be said that this point of view is very effective in the emergence vengeful dissent attitudes. It can be said that teacher candidates can betray their emotions through expressive dissent and teachers can get persuaded through rhetorical dissent.

The item called "I complain my teacher to relieve my anger" received the lowest score with and arithmetic mean of 1.45 (never) within the dimension of expressive dissent. In the expressive dissent dimension, the item called "I am relieved to share my disappointment of the courses with others" received the highest score with an arithmetic mean of 3.16 (sometimes). In the dimension of rhetorical dissent, the item called "I share my concerns with my teacher to get the best grade" received the lowest score with an arithmetic mean of 2,43 (rarely). In the dimension of rhetorical dissent, the item called "I tell the points where I don't agree with my teacher to understand the lesson better" received the highest score with and arithmetic mean of 3.06 (sometimes). Within the dimension of vengeful dissent, the item called "I try to avenge upon my teacher by causing trouble" received the lowest score with an arithmetic mean of 1.11 (never). In the dimension of vengeful dissent, the item called "I try to discredit my teacher by telling his poor practices to others" received the highest score with an arithmetic mean of 1.31 (never).

According to the findings, the items having received the lowest score average show that the ways to harm the teacher in the solution of the problems encountered in the educational process are almost never preferred by the teacher candidates. As indicated by Martin et al. (1998) this situation can be attributed to the fact that the low self efficacy beliefs is determinant in low rhetorical dissent attitudes. Considering the items with the highest score average is examined, it can be said that the approaches such as sharing problems with friends and self - disclosure to teacher are seen in solution of problems; and the reactions to harm teacher are at such a low level that it might never be seen. As indicated by Goodboy and Frisby (2014) a learning - oriented point of view might be the reason of rhetorical dissent. This situation can be interpreted as the existence of self - efficacy and self-development as a result.

\subsection{Findings and Comments on the Second Sub-Problem}

The findings and comments made related to the second sub - problem "Do teacher candidates' academic self efficacy perceptions differ significantly by their gender and department?” are given in Table 4 and Table 5.

Table-4. Mann Whitney U Analysis about academic self - efficacy perceptions according to gender.

\begin{tabular}{|c|c|c|c|c|c|c|}
\hline Dimensions & Gender & $\mathbf{n}$ & Mean Rank & Rank Sum & $\mathbf{U}$ & $\mathrm{p}$ \\
\hline \multirow{2}{*}{ Self-Efficacy Coping } & Female & 235 & 175,67 & $41283, \mathrm{OO}$ & \multirow{2}{*}{10182,00} & \multirow{2}{*}{.039} \\
\hline & Male & 101 & 151,81 & 15333,00 & & \\
\hline \multirow{2}{*}{ Self-Efficacy Effort } & Female & 235 & 174,75 & 41066,00 & \multirow{2}{*}{ 10399,00 } & \multirow{2}{*}{.070} \\
\hline & Male & 101 & 153,96 & 15550,00 & & \\
\hline \multirow{2}{*}{ Self-Efficacy Planning } & Female & 235 & 175,20 & 41173,00 & \multirow{2}{*}{10292,00} & \multirow{2}{*}{.052} \\
\hline & Male & 101 & 152,90 & 15443,00 & & \\
\hline \multirow{2}{*}{ Self-Efficacy Total } & Female & 235 & 175,95 & 41347,50 & \multirow{2}{*}{10117,50} & \multirow{2}{*}{.032} \\
\hline & Male & 101 & 151,17 & 15268,50 & & \\
\hline
\end{tabular}

Source: Calculated from primary data *Level of significance at $\mathrm{p}<0.05$.

When the findings shown in Table 4 are examined, the total scores of the teacher candidates regarding all their academic self - efficacy perceptions and the dimension of coping vary significantly by gender, in favor of female candidates $(\mathrm{p}<.05)$. No significant difference by gender has been detected in other subdimensions of effort and planning $(\mathrm{p}>.05)$. 
The findings show that the perception of female candidates on academic self - efficacy is higher. This situation is similar to the study carried out by Donmuş et al. (2017) and Ekici (2006). It can be said that female teacher candidates are more in the forefront especially in terms of academic self - efficacy. Keskin and Orgun (2006) point out that women behave more emotionally in the use of coping methods their study on self - efficacy, level of competence and coping strategies and they state that there might be gender differences in this sense.

Table-5. Kruskal Wallis Analysis about academic self - efficacy perceptions according to departments.

\begin{tabular}{|c|c|c|c|c|c|}
\hline Departments & $\mathbf{n}$ & Mean Rank & $\mathbf{X}^{2}$ & $d f$ & $\bar{p}$ \\
\hline Computer and Instr. Tech. Teaching & 30 & 156,82 & \multirow{8}{*}{8,571} & \multirow{8}{*}{7} & \multirow{8}{*}{.285} \\
\hline Science Teaching & 40 & 143,60 & & & \\
\hline English Teaching & 33 & 203,73 & & & \\
\hline Primary School Mathematics Teaching & 42 & 158,57 & & & \\
\hline Preschool Teaching & 33 & 171,92 & & & \\
\hline Special Education Teaching & 28 & 159,75 & & & \\
\hline Psychological Counseling and Guidance & 88 & 174,89 & & & \\
\hline Primary School Teaching & 42 & 172,57 & & & \\
\hline Total & 336 & & & & \\
\hline
\end{tabular}

Source: Calculated from primary data *Level of significance at $\mathrm{p}<0.05$.

When the findings given in Table 5 were examined, no significant difference by departments was found between the total scores of teacher candidates taken for all their self - efficacy perceptions $\left(\mathrm{X}^{2}=8,571, d f=7\right.$, $\mathrm{p}=.285)$.

Considering the findings obtained, similarly in the study of Tabancalı and Çelik (2013) there is no significant difference by departments between teacher candidates' academic self - efficacy perceptions. However, Uzun (2016) observed that students' academic self - efficacy perceptions differ by departments. In some departments, he explained the low level of academic self - efficacy in some departments with the difficulty of course contents and he indicated that academic self - efficacy of the students studying in these departments are lower than the others.

\subsection{Findings and Comments on the Third Sub-Problem}

The findings and comments made related to the third sub-problem "Do teacher candidates' instructional dissent attitudes differ significantly by their gender and departments?” are given in Table 6 and Table 7 .

\begin{tabular}{|c|c|c|c|c|c|c|}
\hline Dimensions & Gender & $\mathbf{n}$ & Mean Rank & Rank Sum & $\mathbf{U}$ & p \\
\hline \multirow{2}{*}{ Instructional Dissent Expressive } & Female & 235 & 171,25 & 40244,50 & \multirow{2}{*}{11220,50} & \multirow{2}{*}{.428} \\
\hline & Male & 101 & 162,09 & 16371,50 & & \\
\hline \multirow{2}{*}{ Instructional Dissent Rhetorical } & Female & 235 & 165,98 & 39004,50 & \multirow{2}{*}{11274,50} & \multirow{2}{*}{.467} \\
\hline & Male & 101 & 174,37 & 17611,50 & & \\
\hline \multirow{2}{*}{ Instructional Dissent Vengeful } & Female & 235 & 165,50 & 38892,50 & \multirow{2}{*}{11162,50} & \multirow{2}{*}{.290} \\
\hline & Male & 101 & 175,48 & 17723,50 & & \\
\hline \multirow{2}{*}{ Instructional Dissent Total } & Female & 235 & 169,72 & 39885,00 & \multirow{2}{*}{11580,00} & \multirow{2}{*}{.725} \\
\hline & Male & 101 & 165,65 & 16731,00 & & \\
\hline
\end{tabular}

Source: Calculated from primary data *Level of significance at $\mathrm{p}<0.05$.

When the findings given in Table 6 were examined, no significant difference by gender was found between the total scores of teacher candidates taken for all their instructional dissent attitudes and its subdimensions ( $\mathrm{p}>.05)$.

However, considering the mean ranks by gender within the scope of subdimensions, it is seen that female teacher candidates are at the forefront in their expressive dissent attitudes, while male teacher candidates are at the forefront in their rhetorical and vengeful dissent attitudes. As indicated by Goodboy (2012) who reached similar findings; this situation can be explained by the fact that women tend to explain themselves more against the problems encountered, while men are more direct and aggressive in communication.

Table-7. Kruskal Wallis Analysis about instructional dissent attitudes according to departments.

\begin{tabular}{|c|c|c|c|c|c|}
\hline Departments & $\mathbf{n}$ & Mean Rank & $\mathbf{X}^{2}$ & df & $\mathbf{p}$ \\
\hline Computer and Instr. Tech. Teaching & 30 & 162,90 & \multirow{8}{*}{7,193} & \multirow{8}{*}{7} & \multirow{8}{*}{.405} \\
\hline Science Teaching & 40 & 145,11 & & & \\
\hline English Teaching & 33 & 185,65 & & & \\
\hline Primary School Mathematics Teaching & 42 & 146,40 & & & \\
\hline Preschool Teaching & 33 & 175,52 & & & \\
\hline Special Education Teaching & 28 & 166,61 & & & \\
\hline Psychological Counseling and Guidance & 88 & 177,34 & & & \\
\hline Primary School Teaching & 42 & 180,63 & & & \\
\hline Total & 336 & & & & \\
\hline
\end{tabular}

Source: Calculated from primary data *Level of significance at $\mathrm{p}<0.05$.

When the findings given in Table 7 were examined, no significant difference by departments was found between the total scores of teacher candidates taken for all their instructional dissent attitudes $\left(\mathrm{X}^{2}=7,193, d f=7\right.$, $\mathrm{p}=.409)$.

The fact that no significant difference has been found by departments can be considered as an expected situation. In the study of Özdemir et al. (2018) on the relationship between critical thinking tendencies and 
leadership orientations of teacher candidates which can be compared to a certain degree to instructional dissent attitudes, critical thinking tendencies of teacher candidates did not show any significant difference by departments. Considering that mostly teachers' approaches and teacher candidates' academic self - efficacy believes are effective in emergence of instructional dissent attitudes, as also discussed within the scope of this research, it can be said that such attitudes emerge independently of the department studied.

\subsection{Findings and Comments on the Fourth Sub-Problem}

The findings and comments obtained related to the fourth sub - problem "Is there a relationship between academic self - efficacy perceptions and instructional dissent attitudes of teacher candidates?” are given in Table 8.

Table-8. Spearman's Rank Correlation Analysis showing the relationship between the total scores of teacher candidates' academic self - efficacy perceptions and instructional dissent attitude level.

\begin{tabular}{|c|c|c|c|}
\hline Variable & $\mathbf{n}$ & $\overrightarrow{\mathbf{r}_{\mathrm{s}}}$ & $\mathbf{p}$ \\
\hline Academic Self-Efficacy - Instructional Dissent Expressive & 336 & .046 & .398 \\
\hline Academic Self-Efficacy - Instructional Dissent Rhetorical & 336 & .380 & .000 \\
\hline Academic Self-Efficacy - Instructional Dissent Vengeful & 336 & -.013 & .810 \\
\hline Academic Self-Efficacy - Instructional Dissent Whole & 336 & .218 & .000 \\
\hline
\end{tabular}

Source: Calculated from primary data *Level of significance at $\mathrm{p}<0.05$.

According to Table 8, there is a low level of relationship between the total scores of teacher candidates' academic self - efficacy perception levels and instructional dissent attitude levels. $\left(\mathrm{r}_{\mathrm{s}}=.21, \mathrm{p}=.00\right)$. This situation shows that academic self - efficacy perceptions have a certain extent of effect on the instructional dissent attitudes displayed by teacher candidates. It is seen that there is a stronger relationship between academic self - efficacy perception and the rhetorical dissent dimension of the instructional dissent $\left(\mathrm{r}_{\mathrm{s}}=.38, \mathrm{p}=.00\right)$.

The researchers' belief that negative teacher behaviors cannot be the only factor that started the instructional dissent has played an important role in conducting this study. The fact that a certain extent of relationship has been found between academic self - efficacy and instructional dissent has validated this belief. According to the findings obtained in this sense, one of the factors triggering instructional dissent attitude can be seen as academic self - efficacy perception. According to Martin et al. (2015) low self - efficacy perception adversely affects the emergence of rhetorical dissent attitudes. Considering the findings obtained within the scope of the study, the fact that there is a stronger relationship between academic self - efficacy and rhetorical dissent compared to the whole can be said to support this situation.

\section{Discussion, Conclusion and Recommendation}

In this chapter, academic self - efficacy perceptions and instructional dissent attitudes of the teacher candidates have been evaluated in terms of classroom management within the scope of discussion, conclusions and suggestions.

Teacher candidates have described their academic self - efficacy perception level as intermediate. They have stated that there have some deficiencies particularly at the point of effort. Considering the items related to the dimension of making effort, it can be said that the main reason for teacher candidates to feel weak in this field is that they cannot produce solutions by themselves regarding "what and how to do". Waters et al. (2003) stated that the instructional strategies applied by teachers, classroom management methods and their curriculum design are effective on students' success. It is important that teachers run the course they are responsible for and provide various clues to solve the problems that may be encountered within the scope of the course. It will increase efficiency of teachers to get to know students and try to make students reach the information rather than just transferring the knowledge (Sahin, 2011). According to the results of the study conducted by the Australian Capital Region Council, nine recommendations were made regarding an influential school and one of them is in "effective student assistance center" (Karadağ et al., 2006). Implementation of such a proposal will make it possible for students to see solutions to the problems they encounter and to start to make efforts accordingly.

Considering the findings about instructional dissent attitudes, it can be said that teacher candidates do not exhibit too much behavior accordingly. However, within the scope of the study, there have been traces of expressive dissent and rhetorical dissent. It is important to recognize that dissenting attitudes should not be perceived as a disciplinary problem, but rather as an opportunity for development, and that such attitudes can emerge more clearly in democratic environments. Within the context of classroom management, teachers' behaviors are expected to support democracy within the classroom. As summarized by Martin et al. (1998) the concepts of classroom management and discipline do not have the same meaning. Discipline is the structures and rules defining the behaviors expected from students and it can be seen as efforts to ensure that the students follow these rules. Classroom management can be interpreted as a broader and superior concept as the whole of the efforts of teachers to control learning, social interaction and student behavior. In order to get positive results from these efforts, as stated by Ciftçi (2015) the importance of the effect of teachers' democratic attitudes on students can be emphasized. At present, it can be considered important to develop and maintain democracy in the classroom in order to support rhetorical dissent attitudes which have a positive relationship with academic self - efficacy perception. Democratic classroom environments will also contribute positively to the expressive dissent, which will also help to reveal some problems suppressed.

According to academic self - efficacy perception, some findings that are in favor of female teacher candidates by gender were obtained. It can be mentioned that female teacher candidates qualify themselves as more competent for the whole of coping dimension and academic self - efficacy. Ekici (2012) stated that there is a relationship between academic self - efficacy perception and gender based on related research. Özaydın et al. (2017) pointed out that there are studies showing that there is a difference in favor of women by gender in terms of academic self - efficacy perception and there are also some other studies that have not found out any difference by gender. They explained this situation on the basis of different socio - cultural structures of the samples of studies and different scales used 
in the research. However, in the event that academic self - efficacy perception is high, it is possible to discover one's abilities and try to cope with problems by self - confidence (Öncü, 2012). Teachers are trying to unearth their students' talents and this way to increase student effort towards learning (Bilir, 2014). It is possible for teachers to achieve their learning goals and to follow an effective classroom management process by being a leader and a friend when required, within the framework of student needs (Terzi, 2002). It is possible to discover students' talents in a way that it will help academic self - efficacy increase, to reveal the points where students have difficulty thanks to a student - centered classroom management process, and to produce more specific solutions accordingly. In a student - centered classroom management process, students can be active, and teachers can guide students more effectively by reaching realistic feedbacks.

It has been seen that there is no significant difference in academic self - efficacy perception by departments. However, in some departments which may be considered difficult according to student perceptions, academic self efficacy perception may be low. In such cases, student entry qualifications can be effective. Particularly in the follow - up courses, it will be useful if teachers give place to measuring the subjects that need to be known as pre condition according to their teaching plan prepared within the classroom management process and include practices to complete the deficiencies related to these subjects. In this way, it can be said that academic self efficacy perception and student effort can be improved.

Considering the findings of the study on instructional dissent attitudes, it has been found out that there is no significant difference by gender; however female teacher candidates are more prominent in the expressive dissent. When the approaches towards teachers' classroom management processes are evaluated in general, it can be said that much of a democratic structure is available. In their study, Erdem and Saritaş (2006) mentioned the contributions of teachers' democratic approaches to classroom management processes and made various suggestions for improvement of this situation. One of the suggestions with this regard is putting emphasis on extracurricular problems as well. When the effects of extracurricular self - directed orientation of students are taken into consideration in the perception of academic self - efficacy, the problems with this regard will be detected much more easily with effective communication skills. Furthermore, Dikbaş and Hasırcı (2008) stated that learning strategies increase success of students. In this sense, it can be said that it would be beneficial for teachers to help students express themselves in the classroom management processes and to carry out studies to gain some learning strategies. Not evaluating student attitudes accordingly in a negative framework will contribute to the improvement of in - class democracy and to achieve the learning objectives.

When instructional dissent attitudes were evaluated on the basis of departments, it was observed that there was no significant difference. Therefore, in the light of these findings, the emergence of instructional dissent attitudes is much more related to teacher approaches and student temperaments, rather than the departments. Goodboy and Martin (2014) emphasized that the student neuroticism, being expressionist and acceptability play a determining role in expressive dissent; being expressionist and acceptability in rhetorical dissent and outspokenness, acceptability and inner conscience in vengeful dissent. Considering the impact of teacher approaches in the emergence of all these situations, the importance of maintaining classroom management processes in a democratic environment can be mentioned once more.

In formation of this study, the need to determine the relationship between academic self - efficacy perception and instructional dissent has been effective. When developing the instructional dissent scale, Goodboy (2011) main point of view was to determine the reactive behaviors of students that emerge as a result of negative teacher attitudes. In this study, the relationship between academic self - efficacy perception and instructional dissent has been examined. The fourth sub - problem of the study was created to determine the relationship between academic self - efficacy perception and instructional dissent and a relationship was found with this regard. Particularly, the rhetorical dissent attitudes to emerge as a result of academic competencies, have become more prominent. When the items related to the rhetorical dissent are examined, the effect of students' academic knowledge can be seen. In addition, incorrect practices applied in classroom management processes may also affect this situation from time to time. Kearney et al. (1991) indicated that incorrect teacher practices emerge when teachers are incompetence, offensiveness, and indolence. When teachers are incompetent, they may apply confusing course contents, give unfair grade and hold unsuitable exams; when they are offensiveness, they may humiliate students openly, abuse students physically and verbally; when teachers are indolence, they can come to classroom late, apply ineffective course process and drift away from the curriculum. The co - existence of such situations with academic self efficacy can particularly intensify the rhetorical dissent.

As a result, inappropriate teacher behaviors are determinant in the emergence of instructional dissent attitudes, and academic self - efficacy perception also has a certain extent of effect in emergence of these attitudes. Implementing the classroom management process effectively and conducting an effective teaching process will increase the academic self - efficacy of the students. Frisby et al. (2015) stated that there is a negative relationship between effective classroom management and expressive dissent and a positive relationship between rhetorical dissent and effective teaching strategies and stated that vengeful dissent does not have a relationship with efficiency of the education. With the efficiency of classroom management, the need for expressive dissent attitudes can decrease. With the effectiveness of the instructional strategy, the academic learning process and critical thinking can develop. Naturally rhetorical dissent attitudes can increase.

Important goals of education in the changing and developing World is to improve the students' skills like controlling learning process, actively taking part in the processes and thinking, questioning, taking responsibility, making decisions, etc. Bozpolat (2016). Students' confidence in their own competencies makes a positive contribution to their tasks, and makes them more durable, perseverance and determined to negative situations encountered (Arslan, 2017). In this context, it can be said that teachers are expected to support students' academic development, to make self - evaluation and to approach critical sayings professionally rather than emotionally within the framework of effective classroom management processes. 


\section{References}

Akpınar, E., E. Yıldız and Ö. Ergin, 2006. Attitudes of science teacher candidates towards teaching profession. The Journal of Buca Faculty of Education, 19: $56-62$.

Aktaş, H., 2017. The relationship between academic motivation and academic self-efficacy: An empirical research on the faculty of theology. Journal of the Human and Social Science Researches, 6(3): $1376-1398$.

Aldridge, J. and B. Fraser, 2000. A cross-cultural study of classroom learning environments in Australia and Taiwan. Learning Environments Research, 3(2): 101-134.

Arslan, A., 2017. Investigation of listening anxiety and academic self-efficacy beliefs of secondary school students in terms of various variables. International e-Journal of Educational Studies, 1(1): 12-31.

Bandura, A., 1994. Self-efficacy. In Encyclopedia of human behavior (Ed. Ramachaudran, V., S.). New York: Academic Press, $4: 71$ - 81.

Bandura, A., 1997. Self - efficacy: The exercise of control. New York: Freeman.

Bilir, A., 2014. The tool of success in class management: The precautionary model. Folklore / Literature, 20(78): $203-214$.

Bozpolat, E., 2016. Investigation of the self - regulated learning strategies of students from the faculty of education using ordinal logistic regression analysis. Educational Sciences: Theory \& Practice, 16(1): $301 \quad$ - 318.Available at: https://doi.org/10.12738/estp.2016.1.0281.

Büyüköztürk, Ş., E.K. Çakmak, Ö.E. Akgün, Ş. Karadeniz and F. Demirel, 2013. Scientific research methods. 14th Edn., Ankara: Pegem Academic Publishing.

Celik, İ., H. Sarıçam and S. Sönmez, 2018. Strengths self-efficacy, psychological resilience and perseverance between the relationship [selfefficacy, resilience, and grit]. International Congress on Science and Education 2018 (ICSE2018) Abstract Proceedings, 591.

Ciftçi, A.S., 2015. The relationship between primary school teachers' views on classroom management styles and democratic values. (Published Master's Thesis). Çanakkale: Çanakkale Onsekiz Mart University, Institute of Educational Sciences.

Coban, A. and A. Sanalan, 2002. The effect of the original experimental design process on the self-efficacy perception of the teacher candidate in science teaching class. Journal of Education Faculty, 4(2): 1 - 10.

Dağlı, A., F. Ergül and İ. Kaya, 2017. Adaptation of instructional opposition scale to Turkish: Validity and reliability study. The Journal of Academic Social Science, 5(50): 237 - 251.

Dikbaş, Y. and Ö.K. Hasırcı, 2008. The effect of the teaching of learning strategies and their use in the teaching process on the students' academic achievements and attitudes. Ahi Evran University Journal of Kırşehir Education Faculty, 9(2): 69 - 76.

Donmuş, V., B. Akpınar and M. Eroğlu, 2017. Examining the relationship between prospective teachers' academic self-efficacy and their professional concerns. Mustafa Kemal University, Journal of Social Sciences Institute, 14(37): 1 - 13.

Drago, A., D.C. Rheinheimer and T.N. Detweiler, 2016. Effects of locus of control, academic self-efficacy, and tutoring on academic performance. Journal of College Student Retention: Research, Theory \& Practice, 19(4): 433 - 451 .Available at: https://doi.org/10.1177/1521025116645602.

Ekici, G., 2006. A study on teachers' self-efficacy beliefs of vocational high school teachers. Eurasian Journal of Educational Research, 24: 8796.

Ekici, G., 2012. Academic self-efficacy scale: Adaptation to Turkish, validity and reliability study. Journal of Hacettepe University Faculty of Education, 43(43): 174-185.

Erdem, A.R. and E. Saritaş, 2006. Perceptions of primary school teaching students' perceptions of the democratization of academic staff behavior (PAU sample). Journal of Social Sciences Institute, 16: 525 - 538.

Frisby, B.N., A.K. Goodboy and M. Buckner, M., 2015. Students' instructional dissent and relationships with faculty members' burnout, commitment, satisfaction, and efficacy. Communication Education, 64(1): 65 - 82.Available at: https://doi.org/10.1080/03634523.2014.978794.

Goodboy, A.K., 2011. The development and validation of the instructional dissent scale. Communication Education, 60(4): 422-440.Available at: https://doi.org/10.1080/03634523.2011.569894.

Goodboy, A.K., 2012. Sex differences in instructional dissent. Psychological Reports, 111(1): 189 - 195.Available at: https://doi.org/10.2466/11.07.16.pro.111.4.189-195.

Goodboy, A.K., S.T. Carton, Z.W. Goldman, T.A. Gozanski, W.J. Tyler and N.R. Johnson, 2014. Discouraging instructional dissent and facilitating students' learning experiences through instructor self-disclosure. Southern Communication Journal, 79(2): 114129.Available at: https://doi.org/10.1080/1041794x.2013.865256.

Goodboy, A.K. and B. Frisby, N., 2014. Instructional dissent as an expression of students' academic orientations and beliefs about education. Communication Studies, 65(1): 96 - 111.Available at: https://doi.org/10.1080/10510974.2013.785013.

Goodboy, A.K. and M.M. Martin, 2014. Student temperament and motives as predictors of instructional dissent. Learning and Individual Differences, 32: 266-272.Available at: https://doi.org/10.1016/j.lindif.2014.03.024

Johnson, Z.D. and S. LaBelle, 2014. Examining the role of self-disclosure and connectedness in the process of instructional dissent: A test of the instructional beliefs model. Communication Education, 64(2): 154 - 170.Available at: https://doi.org/10.1080/03634523.2014.978800.

Kandemir, M., 2010. Descriptive model of academic procrastination [A Model Explaining Academic Procrastination Behavior]. (Published PhD Thesis). Ankara: Gazi University Institute of Educational Sciences.

Karadağ, E., N. Baloğlu and P. Yalçınkayalar, 2006. A relational study on the democratic values of primary school administrators and the democratic attitudes of teachers. Journal of Values Education, 4(12): 65-82.

Karasar, N., 2012. Scientific research method. 24th Edn., Ankara: Nobel Academic Publishing.

Kearney, P., T.G. Plax, E.R. Hays and M.J. Ivey, 1991. College teacher misbehaviors: What students don't like about what teachers say and do. Communication Quarterly, 39(4): 309-324.Available at: https://doi.org/10.1080/01463379109369808.

Keskin, G. ̈̈. and F. Orgun, 2006. Examination of coping strategies of students with self-efficacy and proficiency levels [Studying the strategies of students' coping with the levels of self - efficacy - sufficiency]. Anatolian Journal of Psychiatry, 7(2): 92 - 99.

Kotaman, H., 2008. Review of self-efficacy and development of learning performance. Journal of Uludağ University Faculty of Education, 21(1): $111-133$

Martin, M.M., A.K. Goodboy and Z.D. Johnson, 2015. When professors bully graduate students: Effects on student interest, instructional dissent, and intentions to leave graduate education. Communication Education, 64(4): 438-454.Available at: https://doi.org/10.1080/03634523.2015.1041995.

Martin, N.K., Z. Yin and B. Baldwin, 1998. Construct validation of the attitudes \& beliefs on classroom control inventory. The Journal of Classroom Interaction, 33(2): $6-15$.

Öncü, H., 2012. Adaptation of the academic self-efficacy scale to Turkish. Ahi Evran University Journal of Kirsehir Education Faculty, 13(1): 183 - 206.

Özaydın, T.E., P. Çavaş and B.A. Cansever, 2017. Evaluation of self-efficacy beliefs of primary school teachers. Ege Education Journal, 18(1): $1-30$.

Özdemir, Y., H. Buyruk and S. Gungor, 2018. The relationship between prospective teachers' critical thinking dispositions and leadership orientations. Mersin University Journal of the Faculty of Education, 14(2): $548-571$.

Sahin, A., 2011. Effective teacher behaviors according to teacher perceptions. Ahi Evran University Kırşehir Education Faculty Journal, 12(1): 239-259.

Sahin, B., 2012. Methodology. Tanrı̈̆ğen, A. (Editor.), Scientific Research Methods (3rd Edn.,). Ankara: Memorandum Publishing. pp: 109 130 .

Saracaloğlu, A.S., C.A. Karademir, F. Dursun, M. Altın and N. Üstündağ, 2017. The relationship between self-regulatory learning skills, academic self-efficacy, academic locus of control and academic achievement of primary school teacher candidates. Turkish Studies, 12(33): $379-402$.

Simsek, A., 2012. Research models. Simsek, A. (Editor.), Research Methods in Social Sciences (1st Edn.,). Eskisehir: Anadolu University Publishing. pp: $80-107$. 
Sişman, M., H. Güleş and A. Dönmez, 2010. Qualifications framework for a democratic school culture. Uşak University Journal of Social Sciences, 3(1): $167-182$.

Tabancalı, E. and K. Çelik, 2013. The relationship between academic self-efficacy and self-efficacy levels of teacher candidates [the relationship between teacher self-efficacy and teacher self-efficacy]. Journal of Human Sciences, 10(1): 1167-1 184.

Terzi, A.R., 2002. Effective teacher behavior in terms of classroom management. National Education Journal, 155-156: 162-169.

Terzi, A.R. and H. Celik, 2018. The relationship between academic motivation and academic self-efficacy [The relationship of academic motivation and academic self - efficacy of senior students in Necatibey faculty of education]. 6th. International Congress of Social Sciences from China to the Adriatic Full Text Book, Ankara: Institute for Economic Development and Social Research. pp: $84-89$.

Uzun, K., 2016. Predictors of academic self-efficacy: Intolerance to uncertainty, positive belief about anxiety and academic locus of control [Predictors of Academic Self Efficacy: Intolerance of Uncertainty, Positive Beliefs about Worry and Academic Locus of Control] (Published Master's Thesis). Burdur: Mehmet Akif Ersoy University, Institute of Educational Sciences.

Waters, T., R.J. Marzano and B. McNulty, 2003. Balanced leadership: What 30 years of research tells us about the effect of leadership on student achievement. Denver, Colorado: McREL International. Available from https://files.eric.ed.gov/fulltext/ED481972.pdf. 